\title{
Incidence and predictors of COVID-19 and flares in patients with rare autoimmune diseases: a systematic survey and serological study at a national reference center in France
}

Renaud Felten ${ }^{1,2+}$, Marc Scherlinger ${ }^{1,2+}$, Aurélien Guffroy ${ }^{2,3}$, Vincent Poindron ${ }^{2,3}$, Alain Meyer ${ }^{1,2,4}$, Margherita Giannini ${ }^{2,4}$, Anne-Sophie Korganow ${ }^{2,3}$, Christelle Sordet ${ }^{1,2}$, Emmanuel Chatelus ${ }^{1,2}$, Rose-Marie Javier ${ }^{1,2}$, Aurore Meyer $^{2,3}$, Luc Pijnenburg ${ }^{1,2}$, Jean-François Kleinmann 1,2, Jacques-Eric Gottenberg ${ }^{1,2+}$, Jean Sibilia ${ }^{1,2+}$, Thierry Martin ${ }^{2,3+}$ and Laurent Arnaud ${ }^{1,2^{*+}}$ (D)

\begin{abstract}
Background: The risk of severe COVID-19 and its determinants remain largely unknown in patients with autoimmune and inflammatory rheumatic diseases. The objective of this study was to assess the prevalence of COVID-19 infection in patients followed for rare autoimmune diseases as well as the predictors of COVID-19 and disease flare-ups.
\end{abstract}

Methods: Cross-sectional phone survey from April 9, 2020, to July 2, 2020, during which patients with autoimmune diseases followed at the National Reference Center for Rare Autoimmune diseases of Strasbourg were systematically contacted by phone and sent a prescription for a SARS-CoV-2 serology.

Results: One thousand two hundred thirty-two patients were contacted. One thousand fifty-five patients with a confirmed diagnosis of systemic autoimmune disease were included ( 4 unreachable, 4 moves abroad, 5 deaths before pandemic, 50 without consent, and 114 without autoimmune disease). Among them, 469 (44.5\%) patients were tested for SARS-CoV-2 serology.

Thirty-nine patients (7.9\%) had SARS-CoV-2 infection (either through chest CT-scan [n = 5], RT-PCR on nasopharyngeal swab $[n=14]$, or serology $[n=31]$ ) among the 496 who underwent at least one of those 3 diagnosis modalities. Of the 39 proven cases, 33 had clinical manifestations (6 asymptomatic patients were

\footnotetext{
*Correspondence: laurent.arnaud@chru-strasbourg.fr

${ }^{\dagger}$ Renaud Felten, Marc Scherlinger, Jacques-Eric Gottenberg, Jean Sibilia,

Thierry Martin and Laurent Arnaud contributed equally to this work.

'Service de rhumatologie, Service de rhumatologie, Hôpitaux Universitaires

de Strasbourg et Université de Strasbourg, 1 avenue Molière BP 83049, 67098

Strasbourg cedex, France

${ }^{2}$ Centre National de Référence des Maladies Auto-Immunes Systémiques

Rares Est Sud-Ouest (RESO), Strasbourg, France

Full list of author information is available at the end of the article
}

(c) The Author(s). 2021 Open Access This article is licensed under a Creative Commons Attribution 4.0 International License, which permits use, sharing, adaptation, distribution and reproduction in any medium or format, as long as you give appropriate credit to the original author(s) and the source, provide a link to the Creative Commons licence, and indicate if changes were made. The images or other third party material in this article are included in the article's Creative Commons licence, unless indicated otherwise in a credit line to the material. If material is not included in the article's Creative Commons licence and your intended use is not permitted by statutory regulation or exceeds the permitted use, you will need to obtain permission directly from the copyright holder. To view a copy of this licence, visit http://creativecommons.org/licenses/by/4.0/ The Creative Commons Public Domain Dedication waiver (http://creativecommons.org/publicdomain/zero/1.0/) applies to the data made available in this article, unless otherwise stated in a credit line to the data. 


\begin{abstract}
diagnosed through systematic serology testing), 31 were managed by home care, 3 were hospitalized due to a need for oxygenation, two required admission to an intensive care unit, and one died. Among patients with confirmed SARS-CoV-2 infection, reported flares were more frequent than in uninfected patients (26.3\% [10/38] vs. $7.0 \%$ [32/457], $p<0.0001)$. Preventive sick leave had no significant impact on the prevalence of SARS-CoV-2 infection (5.8\% [3/53]) compared to work continuation (7.6\% [30/397], $p=0.64)$. Overall, the seroprevalence of SARS-CoV-2 was 6.6\% (31/469) which was numerically lower to the Grand-Est general population estimated to be $9.0 \%$.
\end{abstract}

Conclusions: This systematic survey of more than 1000 patients with rare systemic autoimmune diseases reports a low prevalence of proven SARS-CoV-2 infection and very rare severe infections, probably related to good compliance with prophylactic measures in these patients.

Keywords: Autoimmune diseases, Epidemiology, Immune system diseases, COVID-19

\section{Introduction}

The severe acute respiratory syndrome coronavirus-2 (SARS-CoV-2) pandemic began in December 2019 in Wuhan, China, and then spread around the globe, affecting every continent. At an early stage of the pandemic, chronically ill and/or immunocompromised patients were identified as at-risk patients for the coronavirus disease-2019 (COVID-19). Patients with rare autoimmune diseases, often treated with immunosuppressive drugs, were included in this at-risk group.

The French region "Grand-Est" represents more than 5.5 million people. This area was the most early and the most heavily affected area in France [1]. A wave of contamination emerged at the end of February 2020, leading to a national lockdown between March 17th and May 11th, 2020. Our tertiary center in Strasbourg is the only French national referral center for rare systemic and autoimmune diseases in the "Grand Est" area.

The SARS-CoV-2 is a new virus and COVID-19 a new disease. People with rare autoimmune diseases appropriately confronted their rheumatologists with questions such as their potential increased risk of severe disease and whether lowering immunosuppressive drugs, shielding, and/or preventive sick leave would be appropriate. In this regard, national and international recommendations have been published [2]. However, it is important to rapidly accrue scientific knowledge, and methodologically robust information is crucially needed since COVID-19 is nowhere near extinguished [2].

The main objective of our study was to assess the prevalence of documented and undocumented SARSCoV-2 infection in patients followed for rare autoimmune diseases and to assess the predictors of COVID-19 as well as the risk of disease flare-ups in the context of potential changes in treatments in these patients. Our secondary objective was to compare this prevalence to the general population in our area at the same time.

\section{Methods}

Study design and patients for Strasbourg National Reference Center for Autoimmune Diseases

We performed a cross-sectional phone survey, during which patients with autoimmune diseases followed at the National Reference Center for Rare Autoimmune Diseases of Strasbourg (CRMR RESO) were systematically contacted by phone by trained medical students, research assistants, and co-authors (up to 3 times in case they did not answer the initial call). In case of absence of response, the general practitioner and patient relatives were called in order to inquire about the patient health or whereabouts (move to another area/country, death and its cause). Patients with autoimmune diseases were identified from a comprehensive computerized list from the CRMR RESO. This list was extensively reviewed by the medical team and the clinical files checked when needed to ensure the inclusion of patients with a confirmed diagnosis of autoimmune disease (patients with suspected diseases were excluded). These diseases included systemic lupus erythematosus, Sjögren's syndrome, systemic sclerosis, idiopathic inflammatory myopathies, juvenile idiopathic arthritis, vasculitis, overlap syndromes, primary antiphospholipid syndrome, sarcoidosis, Behçet's disease, mixed connective tissue disorder, relapsing polychondritis, undifferentiated connective tissue disorder, Still's disease, and Shulman's disease. Inflammatory rheumatic diseases (e.g., rheumatoid arthritis and spondyloarthritis) were not included in our study. Following information regarding the methodology and general purpose of the study, patients who consented to participate were assessed during a phone survey using a standardized questionnaire which collected their demographic characteristics, known risk factors for COVID-19, potential exposure to SARS-CoV-2, preventive sick leave, symptoms of COVID-19, current treatments (including self- or medically prescribed changes in those treatments due to the pandemic), documented SARS-CoV-2 infection status (and the detailed means of 
confirmation), and main outcomes in case of SARS$\mathrm{CoV}-2$ infection. Reported flare of the autoimmune condition was evaluated by asking the patient if she/he experienced symptoms compatible with a flare and if so, which one. A reported flare was considered present if the reported symptoms were compatible with a flare of the disease. Patients were also sent information regarding the methodology, general purpose of the study, and a prescription for a SARS-CoV-2 serology to be conducted in their local laboratory. If they accepted to be serologically tested, they signed a written consent to participate to the study. The telephone survey took place from April 9, 2020, to July 2, 2020. Non-centralized serologic tests were conducted between May 18, 2020, and July 2, 2020. The study was approved by the ethics committee of Strasbourg (\#CE-2020-50).

In order to compare the seroprevalence of SARS-CoV2 infection in our cohort of patient with autoimmune disease to the seroprevalence in the general population of the Grand-Est area, we used the results of the seroprevalence study of Carrat et al. [3].

\section{Statistical analysis}

For descriptive statistics, continuous variables were presented as median and interquartile range (IQR) and categorical variables as numbers and percentages. Comparison between groups was performed using the $x^{2}$ test (or Fisher's exact test when appropriate) for categorical variables and the Mann-Whitney test for continuous variables. Multivariate analysis was performed to assess the association between documented COVID-19 cases (dependent variables) and potential predictors ( $\mathrm{p}$ values $<0.10$ in univariate analysis). All tests were bilateral, using an alpha risk of 0.05 . Statistical analyses were performed using the software JMP 13 (SAS Institute, USA).

\section{Results}

Based on active cohorts followed at our National Reference Center, a total of 1232 patients were contacted by phone (Fig. 1). Fourteen patients could not be reached. Among them, general practitioner or relatives informed us of one death due to SARS-CoV-2 (included in the outcome analysis), 5 deaths of other causes, 4 moves abroad, and 4 patients for whom they could not provide information.

Fifty patients did not consent to participate; $114 \mathrm{pa}$ tients were excluded because they did not have a confirmed autoimmune disease (flowchart Fig. 1).

In total, 1055 patients with a confirmed diagnosis of systemic autoimmune disease were included. There were 840 women $(79.6 \%)$ with a median age of 53 years (IQR 37-65). Among them, 469 (44.5\%) patients were tested for SARS-CoV-2 serology. Detailed demographic characteristics, autoimmune disease diagnosis, known risk factors for COVID-19, potential exposure to SARS-CoV2, use of protective measures, symptoms of COVID-19, and current treatments are summarized in Table 1.

Two hundred and one (19.1\%) patients reported a selfsuspected SARS-CoV2 infection. However, only 39 (7.9\%) had proven SARS-CoV-2 infection (either through chest CT-scan [ $\mathrm{n}=5]$, nasopharyngeal RT-PCR $[\mathrm{n}=15]$, or serology $[\mathrm{n}=31])$ among the 495 who underwent at least one of those 3 diagnosis modalities (Fig. 1). Among confirmed cases, 33 had clinical manifestations of COVID-19 [4] (6 asymptomatic patients were diagnosed through systematic serology testing). Of the 39 proven cases, 31 were managed by home care, 3 were hospitalized due to a need for oxygenation, 2 required admission to an intensive care unit, and one died. Among the 5 patients with SARS-Cov2 infection proven by CT-scan, all also had a positive RT-PCR and/or a positive serology.

Considering the 136 patients who reported having clinical signs suggestive of SARS-CoV-2 infection and who were serologically tested, $25(18.4 \%)$ had a positive SARS-CoV-2 serology.

Overall, the seroprevalence of SARS-CoV-2 was 6.6\% $(31 / 469)$ which was numerically but not significantly lower to the Grand-Est general population estimated to be $9.0 \%(270 / 3434, \mathrm{p}=0.34)$ by Carrat et al. [3].

The frequency of SARS-CoV-2 infection (confirmed by chest CT-scanner, RT-PCR and/or serology) did not differ significantly between patients with preventive sick leave $(3 / 52,5.8 \%)$ and those without $(30 / 397,7.6 \%), p=$ 0.64 .

Comparisons of patients' characteristics with and without confirmed SARS-CoV-2 infection are shown in Table 2. Prevalence of positive COVID-19 serology in each autoimmune systemic disease is provided in supplementary Table 1.

Patients in whom there was a change in the immunosuppressive treatment during the pandemic were more likely to report a flare of the autoimmune disease (48\% [35/73] vs. $13.4 \%$ [131/981], $\mathrm{p}<0.0001)$. Among patients with confirmed SARS-CoV-2 infection, flares were more frequent than in uninfected patients $(26.3 \%$ [10/38] vs. $7.0 \%$ [32/457], $\mathrm{p}<0.0001)$.

\section{Discussion}

To date, there is no evidence that patients with rare autoimmune disease face more risk of contracting SARS-CoV-2 than individuals without such disease, nor that they have a worse prognosis $[2,5]$. Our study involves a large single-center cohort of more than 1000 patients with rare autoimmune and systemic diseases in the time of SARS-CoV-2 pandemics. Its main strengths are a very little rate of missing clinical data $(<0.4 \%)$, its localization in one of the highest SARS-CoV-2 


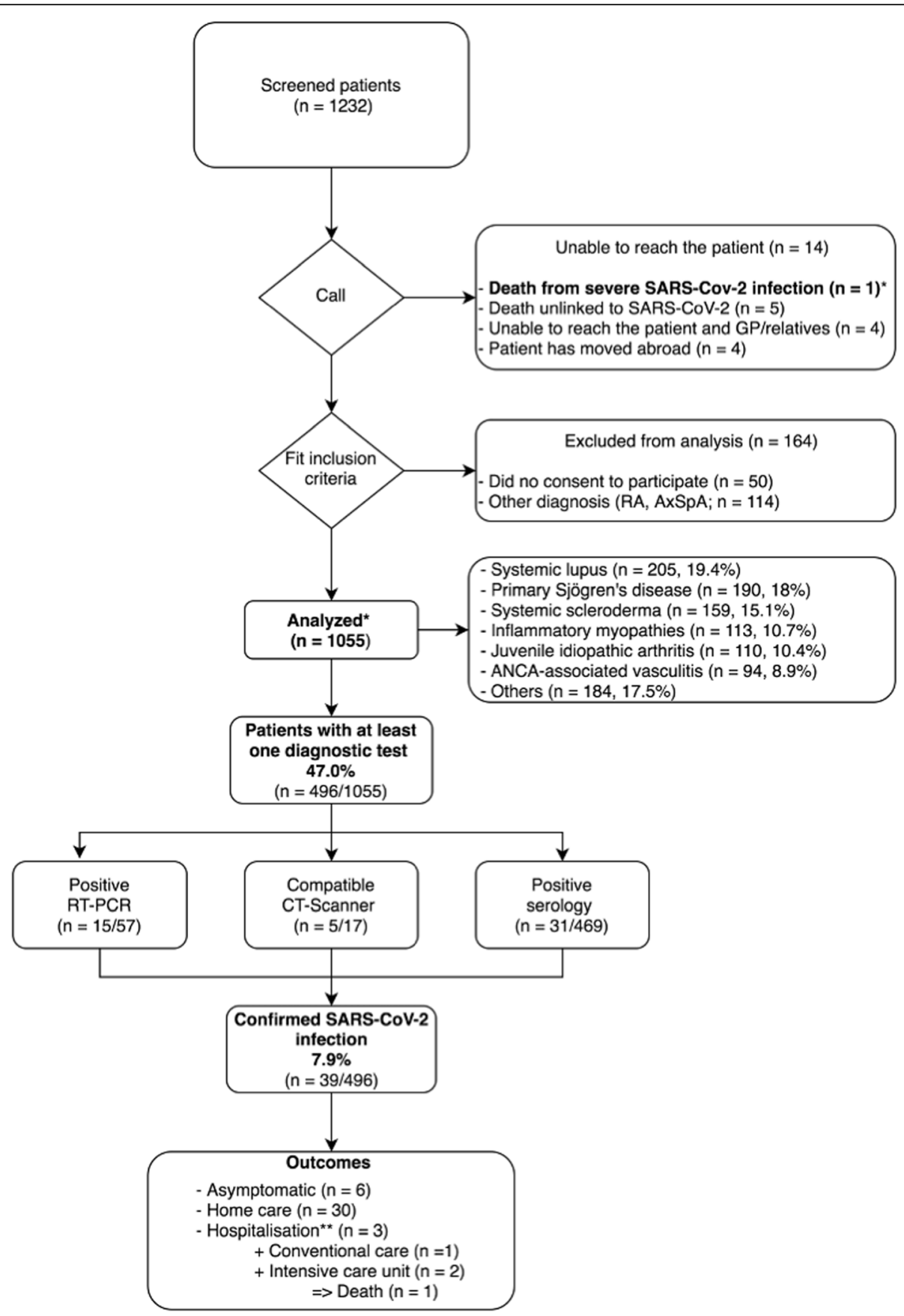

Fig. 1 Flow chart of the study and prevalence and outcomes of confirmed SARS-CoV-2 infections. Single asterisk indicates that the unreached patient dead from SARS-CoV-2 was included in the outcome analysis. Double asterisks indicate that all hospitalized patients have been discharged home at the time of the study writing

prevalence area in France, and the addition of serologic data. As summarized in Fig. 1, we focused on finding evidence for each patient in our cohort and understanding why we could not reach some of them. We were able to retrieve information (moves, deaths unrelated to COVID-19) and even one death because of a severe SARS-CoV-2 infection in a 78-year-old woman with primary Sjögren's syndrome. Only 4 patients could not be reached even through their general practitioner and relatives. Our study has also limits. First, we cannot exclude that some of the 4 patients without information even through their general practitioner have had SARSCoV-2 infection. However, they represent less than $0.4 \%$ of the cohort making it unlikely to significantly alter our 
Table 1 Demographic characteristics, autoimmune disease diagnosis, known risk factors for COVID-19, potential exposure to SARSCoV-2, use of protective measures, symptoms of COVID-19, current treatments and modifications, flares, and serological status for SARS-CoV-2

\section{Patient characteristics}

Age (years), median [IQR25-75]

$53(37-65)$

Female, $\mathrm{n}(\%)$

$840(79.6 \%)$

AISD diagnosis, $\mathbf{n}(\%)$

Lupus

205 (19.4)

Sjögren

190 (18)

Systemic sclerosis

$159(15.1)$

IM

$113(10.7)$

$J / A$

$110(10.4)$

Vasculitis

$94(8.9)$

Overlap syndrome

$84(8.0)$

Primary APS

$33(3.1)$

Sarcoidosis

$26(2.5)$

Behçet

$15(1.4)$

MCTD

$14(1.3)$

Other

Benefited from preventive work cessation, $\mathrm{n}(\%)$

At least one contact with a confirmed COVID-19 case, $n(\%)$

Self-suspected SARS-CoV-2 infection (according to the patient him/herself), $n(\%)$

Self-reported SARS-CoV-2 infection symptoms, $n(\%)$

$/ 1054$

Fever

$89(8.4)$

Chills

$62(5.9)$

Myalgia

$86(8.2)$

Cough/dyspnea

$133(12.6)$

Thoracic pain/oppression

$39(3.9)$

Gastroenteritis

$54(5.1)$

Anosmia

$42(4.0)$

Thrombosis

$1(0.09)$

Risk factors for SARS-CoV-2 infection (history of), $\mathrm{n}(\%)$

$/ 1054$

Cancer

$49(4.6)$

Cardiac failure

$34(3.2)$

Myocardial infarction

$29(2.7)$

Diabetes

$71(6.7)$

Hypertension

$250(23.7)$

Cerebrovascular event

$47(4.5)$

Respiratory failure

$126(12.0)$

Renal failure

$65(6.2)$

Hepatic insufficiency

$43(4.1)$

$24.4(21.2-28.7)$

BMI $\left(\mathbf{k g} / \mathbf{m}^{2}\right)$, median [IQR25-75]

$53(5.7)$

$B M I>40$

$19(2.1)$

Smoking status, $\mathrm{n}(\%)$

1973

Current smoker 
Table 1 Demographic characteristics, autoimmune disease diagnosis, known risk factors for COVID-19, potential exposure to SARSCoV-2, use of protective measures, symptoms of COVID-19, current treatments and modifications, flares, and serological status for SARS-CoV-2 (Continued)

\begin{tabular}{|c|c|}
\hline Patient characteristics & \\
\hline Former smoker & $273(28.1)$ \\
\hline Never smoker & $571(58.7)$ \\
\hline Treatments, n (\%) & $/ 1054$ \\
\hline NSAIDs & $81(7.7)$ \\
\hline Glucocorticoids & $289(27.4)$ \\
\hline Antimalarials (HCQ/CQ) & $262(24.9)$ \\
\hline Immunosuppressive agents/biologics & $447(42.4)$ \\
\hline Treatment modification due to pandemic, n (\%) & 73/1054 (6.9) \\
\hline Reporting a flare-up of AISD (self-diagnosed), n (\%) & 166/1054 (15.7) \\
\hline \multicolumn{2}{|l|}{ Serological status for SARS-CoV-2, $\mathrm{n}(\%)$} \\
\hline Positive lgG and/or Ig $M$ & $31 / 469(6.6)$ \\
\hline
\end{tabular}

conclusions. Second, this study was a telephonic survey and recorded information such as symptoms suggestive of SARS-Cov2 infection or disease flares were declarative and not confirmed through clinical examination. This limit could hardly be prevented since the study was conducted during the pandemics peak and the general lockdown, but we chose robust arguments to define SARS-CoV-2 infection (nasopharyngeal swab RT-PCR and/or chest CT-scan and/or serology) to avoid this caveat. Serology was performed between 1 and 4 months after the end of the 1st wave in Grand Est, a delay allowing the development of a humoral response against SARS-CoV-2 [6]. To note, all patients diagnosed using chest CT-scan were also positive for RT-PCR or serology, as chest CT-scan might have limited specificity in patients with systemic autoimmune disease [7]. Finally, only $27.9 \%$ (56/201) of symptomatic patients were tested with a nasopharyngeal swab RT-PCR. In fact, at the time of the study, testing capacities in France were very low, and RT-PCR was prioritized for severe patients and healthcare practitioners.

Completing other published studies [8], our results allow to estimate the prevalence of SARS-CoV-2 infection in a large group of patients with rare autoimmune and systemic diseases, 7.9\% (39/496). Among them, 33 patients developed clinical manifestations, three patients were hospitalized $(3 / 1054,0.28 \%)$ including 2 in an intensive care unit $(2 / 1055,0.19 \%)$, and one died. These results appear comparable to the general population of the same area on July 2: $0.32 \%$ for hospitalization (17893/5.5 million) [9].

The numerically lower seroprevalence of SARS-CoV-2 (6.6\% versus $9 \%$ ) observed among patients with systemic autoimmune diseases compared to the local general population [3] may be explained by the fact that these patients rigorously followed the preventive and control measures or that some patients did not develop humoral immunity. In fact, two patients in our cohort with RTPCR-confirmed SARS-CoV-2 infection had a negative serology more than 4 weeks after infection. One had been treated with rituximab/chloraminophen for a MALT lymphoma 4 years before, and one was currently treated with methotrexate/hydroxychloroquine for a rhupus diagnosis. While bearing in mind that our study is retrospective and declarative, our results do not support the prescription of preventive sick leave and lowering of immunosuppressive treatments, as underlined in many recommendations from scientific societies [2]. In France, people with significant immunosuppression/serious medical conditions were not asked to take additional precautions to protect themselves from COVID19. All fragile people, at risk of severe COVID-19, were required to strictly adhere to the "barrier measures" and could be put on preventive sick leave if this was not possible at their workplace. It is possible that at an individual level, some patient did shield which would significantly affect their exposure to SARS-COV2. However, it is also the case for patients without immunosuppression (e.g., suffering from hypertension, cardiovascular diseases, and even osteoarthritis or osteoporosis) which also "shielded" on their initiative, therefore limiting the potential bias.

Due to the low number of confirmed cases, we could not analyze risk factors for infection or the impact of disease-modifying therapies on the risk of SARS-CoV-2infection. Available data suggest that patients treated with traditional immunosuppressive drugs, bDMARDs 
Table 2 Demographic characteristics, autoimmune disease diagnosis, risk factors for SARS-CoV-2 infection, and current treatments

\begin{tabular}{|c|c|c|c|}
\hline & $\begin{array}{l}\text { Patients with a confirmed } \\
\text { SARS-CoV- } 2 \text { infection, } n=39\end{array}$ & $\begin{array}{l}\text { Non-infected patients } \\
n=457\end{array}$ & $\mathrm{p}$ \\
\hline Age (years), median [IQR25-75] & $56.9(47.6-65.9)$ & $56.9(43.5-67.2)$ & 0.80 \\
\hline Female, $n(\%)$ & $29(74.4 \%)$ & $363(79.4 \%)$ & 0.42 \\
\hline Preventive work cessation, $\mathrm{n}(\%)$ & $3(9.1 \%)$ & $49(11.8 \%)$ & 0.64 \\
\hline At least one contact with a confirmed COVID-19 case, $n(\%)$ & $16(42.1 \%)$ & $27(5.9 \%)$ & $<0.0001$ \\
\hline $\begin{array}{l}\text { Self-suspected SARS-CoV-2 infection } \\
(\mathrm{n}=201) \text { (according to the patient him/herself), } n(\%)\end{array}$ & $32(84.2 \%)$ & $122(26.8 \%)$ & $<0.0001$ \\
\hline \multicolumn{4}{|l|}{$\begin{array}{l}\text { Risk factors for SARS-CoV-2 infection } \\
\text { (history of), } n(\%)^{[1054]}\end{array}$} \\
\hline Cancer & $2(7.9 \%)$ & $25(5.5 \%)$ & 0.53 \\
\hline Cardiac failure & $1(2.6 \%)$ & $14(3.1 \%)$ & 0.88 \\
\hline Myocardial infarction & 0 & $15(3.3 \%)$ & 0.26 \\
\hline Diabetes & $1(2.6 \%)$ & $30(6.6 \%)$ & 0.34 \\
\hline Hypertension & $9(23.7 \%)$ & $126(27.6 \%)$ & 0.61 \\
\hline Cerebrovascular event & $3(7.9 \%)$ & $24(5.3 \%)$ & 0.49 \\
\hline Respiratory failure & $5(13.2 \%)$ & $70(15.3 \%)$ & 0.72 \\
\hline Renal failure & $2(5.3 \%)$ & $36(7.9 \%)$ & 0.56 \\
\hline Hepatic insufficiency & $2(5.3 \%)$ & $20(4.4 \%)$ & 0.80 \\
\hline BMI $\left(\mathbf{k g} / \mathbf{m}^{2}\right)$, median [IQR25-75] & $24.2(21.3-28.2)$ & $24.8(21.5-28.7)$ & 0.36 \\
\hline$B M I>35$ & $2(5.4 \%)$ & $31(7.7 \%)$ & 0.62 \\
\hline$B M I>40$ & 0 & $13(3.2 \%)$ & 0.27 \\
\hline Smoking status, $\mathrm{n}(\%)$ & & & 0.13 \\
\hline Current smoker & $1(2.8 \%)$ & 65 (15.0\%) & \\
\hline Former smoker & $13(36.1 \%)$ & $141(32.5 \%)$ & \\
\hline Never smoker & $22(61.1 \%)$ & $228(52.5 \%)$ & \\
\hline Smoking ever & $14(38.9 \%)$ & $206(47.5 \%)$ & 0.32 \\
\hline \multicolumn{4}{|l|}{ Treatments, $n(\%)^{[1054]}$} \\
\hline NSAIDs & $5(13.2 \%)$ & $28(6.1 \%)$ & 0.09 \\
\hline Glucocorticoids & $9(23.7 \%)$ & $135(29.6 \%)$ & 0.44 \\
\hline Antimalarials (HCQ/CQ) & $14(36.8 \%)$ & $131(28.7 \%)$ & 0.29 \\
\hline Immunosuppressive agents/biologics & $15(39.5 \%)$ & $195(42.6 \%)$ & 0.70 \\
\hline Treatment modification due to pandemic, $n(\%)$ & $10(26.3 \%)$ & $32(7.0 \%)$ & $<0.0001$ \\
\hline Reporting a flare-up of AISD (self-diagnosed), n (\%) & $13(34.2 \%)$ & $58(12.7 \%)$ & 0.0003 \\
\hline \multicolumn{4}{|l|}{ Serological status for SARS-CoV-2, n (\%) } \\
\hline Positive $\lg G$ and/or Ig $M$ & $31 / 33(93.9 \%)$ & 0 & $<0.0001$ \\
\hline
\end{tabular}

or tsDMARDs, are not at increased risk of severe COVID-19 [10, 11] and that hydroxychloroquine has no significant protective effect [12].

Immunosuppressive treatment modification, whether due to proven infection or not, were significantly associated with self-declared disease flares but also with confirmed SARS-CoV-2 infections. Giving our results, it is impossible to know "which came first: the chicken or the egg?". What we observed is that most patients modifying their immunosuppressive treatment did not have a confirmed SARS-CoV-2 infection (76.1\%, 32/42). In addition, among patients with a confirmed SARS-CoV-2 infection, only about a quarter have modified their immunosuppressive treatment $(26.3 \%, 10 / 38)$. Finally, of the 13 patients with a confirmed infection and who also experimented flares, 7 (53.9\%) have modified their immunosuppressive treatments.

\section{Limitations}

Since we did not ask this specific question about the reason for the treatment modification due to a possible shortage, we cannot exclude that some drug shortages 
may have impacted flare rates in our study. Finally, this study was led by the French national referral center for rare systemic diseases (CRMR RESO) which aims to study rare systemic diseases. Hence, more frequent diseases such as rheumatoid arthritis and spondyloarthritis were not included in our study.

Only 25 of $136(18.4 \%)$ serologically tested patients who reported having clinical signs suggestive of SARSCoV-2 infection had a positive serology. These data suggest that most patients reporting symptoms did not encounter the virus (or did not develop a humoral response for unexplained reasons). Patients' perception of their health in time of pandemics may be greatly influenced by the media. A nocebo effect caused by the context of the pandemics may be responsible for nonspecific symptoms (headache, dyspnea, cough, etc.) [7]. Moreover (and non-exclusively), a cognitive bias known as incorrect causal attribution bias makes one likely, in time of great stress induced by the pandemics, to attribute non-specific symptoms to a specific diagnosis such as COVID-19 infection, even without objective proof of it [13].

\section{Conclusion}

This systematic survey of more than 1000 patients with rare systemic autoimmune diseases reports a low prevalence of proven SARS-CoV-2 infection of $7.9 \%$ and very rare severe infections that may be related to good compliance with prophylactic measures in these patients. Our study may help better tailor patient recommendation in the settings of the SARS-CoV-2 pandemics.

\section{Supplementary Information}

The online version contains supplementary material available at https://doi. org/10.1186/s13075-021-02565-0.

Additional file 1. Supplementary table 1: comparison of the prevalence of a positive SARS-CoV-2 serology between rare autoimmune diseases.

\section{Acknowledgements}

We are indebted to all patients for their kind participation in our study. We also thank the following medical students for providing help to contact patients by phone: Marine Grosjean, Alia Harba, Arthur Krantz, Lucie Wilt, Simon Rohmer, Fanny Nass, Clara Trautmann, Clément Pflieg, Elisa Vogel, and Soumaya Chaffai.

We acknowledge Sylvie Thuong, Valle Meyer, Tahous Sehili, and Alice Borges, our medical assistants, and Yazhuo Gong and Hélène Merlin, our research assistants, for their help in the conduction of the study.

We thank the European Reference Network for Rare Immunodeficienty, AuToinflammatory and Autoimmune Diseases (ERN RITA) and Rare CONnective Tissue and Musculoskeletal Diseases European Reference NETwork (ERN ReCONNET).

\section{Authors' contributions}

Renaud Felten, Marc Scherlinger, Aurélien Guffroy, Vincent Poindron, Alain Meyer, Margherita Giannini, Anne-Sophie Korganow, Christelle Sordet, Emmanuel Chatelus, RoseMarie Javier, Aurore Meyer, Luc Pijnenburg, JeanFrançois Kleinmann, Jacques-Eric Gottenberg, Jean Sibilia, Thierry Martin, Laurent Arnaud
- Jean-François Kleinmann, Jacques-Eric Gottenberg, Jean Sibilia, Thierry Martin, Laurent Arnaud: conceptualization;

- Jean-François Kleinmann, Laurent Arnaud: data curation;

- Renaud Felten, Marc Scherlinger, Aurélien Guffroy, Vincent Poindron, Alain

Meyer, Margherita Giannini, Anne-Sophie Korganow, Christelle Sordet, Emmanuel Chatelus, RoseMarie Javier, Aurore Meyer, Luc Pijnenburg, Jacques-Eric Gottenberg, Thierry Martin, Laurent Arnaud: investigation; - Renaud Felten, Marc Scherlinger, Jean-François Kleinmann, Jacques-Eric Gottenberg, Jean Sibilia, Thierry Martin, Laurent Arnaud: methodology;

- Jean-François Kleinmann, Jacques-Eric Gottenberg, Jean Sibilia, Thierry Martin, Laurent Arnaud: project administration:

- Jean-François Kleinmann, Jacques-Eric Gottenberg, Jean Sibilia, Thierry Martin, Laurent Arnaud: resources;

- Jean-François Kleinmann, Jacques-Eric Gottenberg, Jean Sibilia, Thierry Martin, Laurent Arnaud: supervision;

- Renaud Felten, Marc Scherlinger, Aurélien Guffroy, Vincent Poindron, Alain Meyer, Margherita Giannini, Anne-Sophie Korganow, Christelle Sordet, Emmanuel Chatelus, RoseMarie Javier, Aurore Meyer, Luc Pijnenburg, JeanFrançois Kleinmann, Jacques-Eric Gottenberg, Jean Sibilia, Thierry Martin, Laurent Arnaud: validation;

- Renaud Felten, Marc Scherlinger, Laurent Arnaud: writing —original draft; - Renaud Felten, Marc Scherlinger, Aurélien Guffroy, Vincent Poindron, Alain Meyer, Margherita Giannini, Anne-Sophie Korganow, Christelle Sordet, Emmanuel Chatelus, RoseMarie Javier, Aurore Meyer, Luc Pijnenburg, JeanFrançois Kleinmann, Jacques-Eric Gottenberg, Jean Sibilia, Thierry Martin, Laurent Arnaud: writing - review and editing.

The authors read and approved the final manuscript.

Funding

None

Availability of data and materials

All data relevant to the study are included in the article or uploaded as supplementary information.

\section{Declarations}

Ethics approval and consent to participate

The study was approved by the ethics committee of Strasbourg (\#CE-202050).

Consent for publication

All participants in this study have consented for publication.

Competing interests

There is no competing interest for any author.

\section{Author details}

'Service de rhumatologie, Service de rhumatologie, Hôpitaux Universitaires de Strasbourg et Université de Strasbourg, 1 avenue Molière BP 83049, 67098 Strasbourg cedex, France. ${ }^{2}$ Centre National de Référence des Maladies Auto-Immunes Systémiques Rares Est Sud-Ouest (RESO), Strasbourg, France. ${ }^{3}$ Service d'immunologie clinique et médecine interne, Hôpitaux Universitaires de Strasbourg et Université de Strasbourg, Strasbourg, France. ${ }^{4}$ Service de physiologie et explorations fonctionnelles, Hôpitaux Universitaires de Strasbourg et Université de Strasbourg, Strasbourg, France.

Received: 28 January 2021 Accepted: 24 June 2021

Published online: 13 July 2021

\section{References}

1. Salje H, Kiem CT, Lefrancq N, Courtejoie N, Bosetti P, Paireau J, et al. Estimating the burden of SARS-CoV-2 in France. Science. 2020;369(6500): 208-11.

2. Landewé RB, Machado PM, Kroon F, Bijlsma HW, Burmester GR, Carmona L, et al. EULAR provisional recommendations for the management of rheumatic and musculoskeletal diseases in the context of SARS-CoV-2. Ann Rheum Dis. 2020;79(7):851-8. https://doi.org/10.1136/annrheumdis-2020-21 7877

3. Carrat F, de Lamballerie X, Rahib D, Blanche H, Lapidus N, Artaud F, et al. Seroprevalence of SARS-CoV-2 among adults in three regions of France 
following the lockdown and associated risk factors: a multicohort study. medRxiv. 2020; 2020.09.16.20195693.

4. Guan W-J, Ni Z-Y, Hu Y, Liang W-H, Ou C-Q, He J-X, et al. Clinical characteristics of coronavirus disease 2019 in China. N Engl J Med. 2020; 382(18):1708-20.

5. Faye AS, Lee KE, Laszkowska M, Kim J, Blackett JW, McKenney AS, et al. Risk of adverse outcomes in hospitalized patients with autoimmune disease and COVID-19: a matched cohort study from New York city. J Rheumatol. 2020.

6. Ripperger TJ, Uhrlaub JL, Watanabe M, Wong R, Castaneda Y, Pizzato HA, et al. Orthogonal SARS-CoV-2 serological assays enable surveillance of lowprevalence communities and reveal durable humoral immunity. Immunity. 2020; [cité 10 nov 2020]; Disponible sur: http:/www.sciencedirect.com/ science/article/pii/S1074761320304453.

7. Eslambolchi A, Aghaghazvini L, Gholamrezanezhad A, Kavosi H, Radmard AR. Coronavirus disease 2019 (COVID-19) in patients with systemic autoimmune diseases or vasculitis: radiologic presentation. J Thromb Thrombolysis. 2020:1-10.

8. Gianfrancesco M, Hyrich KL, Al-Adely S, Carmona L, Danila Ml, Gossec L, et al. Characteristics associated with hospitalisation for COVID-19 in people with rheumatic disease: data from the COVID-19 Global Rheumatology Alliance physician-reported registry. Ann Rheum Dis. 2020;79(7):859-66.

9. SPF. COVID-196: point épidémiologique en Grand Est du 2 juillet 2020 [Internet]. [cité 10 nov 2020]. Disponible sur:/regions/grand-est/documents/ bulletin-regional/2020/covid-19-point-epidemiologique-en-grand-est-du-2juillet-2020

10. Salvarani C, Bajocchi G, Mancuso P, Galli E, Muratore F, Boiardi L, et al. Susceptibility and severity of COVID-19 in patients treated with bDMARDS and tsDMARDs: a population-based study. Ann Rheum Dis. 2020;79(7):9868. https://doi.org/10.1136/annrheumdis-2020-217903.

11. Monti S, Balduzzi S, Delvino P, Bellis E, Quadrelli VS, Montecucco C. Clinical course of COVID-19 in a series of patients with chronic arthritis treated with immunosuppressive targeted therapies. Ann Rheum Dis. 2020;79(5):667-8.

12. Konig MF, Kim AH, Scheetz MH, Graef ER, Liew JW, Simard J, et al. Baseline use of hydroxychloroquine in systemic lupus erythematosus does not preclude SARS-CoV-2 infection and severe COVID-19. Ann Rheum Dis. 2020; 79(10):1386-8

13. Ongaro G, Howick J. Coronavirus: could reading about the pandemic cause harm? Conversation. [cité 15 oct 2020]. Disponible sur: http://theconversa tion.com/coronavirus-could-reading-about-the-pandemic-cause-harm-13 5585

\section{Publisher's Note}

Springer Nature remains neutral with regard to jurisdictional claims in published maps and institutional affiliations.

Ready to submit your research? Choose BMC and benefit from:

- fast, convenient online submission

- thorough peer review by experienced researchers in your field

- rapid publication on acceptance

- support for research data, including large and complex data types

- gold Open Access which fosters wider collaboration and increased citations

- maximum visibility for your research: over $100 \mathrm{M}$ website views per year

At $\mathrm{BMC}$, research is always in progress.

Learn more biomedcentral.com/submissions 